INTERDISCIPLINARIA ARCHAEOLOGICA

Thematic review

\title{
Space Matters: A Reflection on Archaeological Theory and Method for Interpreting the Materiality of Space
}

\author{
Monika Baumanováa,b* \\ ${ }^{a}$ Centre for African Studies, University of Basel, Rheinsprung 21, 4051 Basel, Switzerland \\ ${ }^{b}$ Department of Archaeology and Ancient History, University of Uppsala, Engelska Parken, Thunbergsvägen 3H, 75126 Uppsala, Sweden
}

\section{A RTICLE INFO}

\section{Article history:}

Received: $22^{\text {nd }}$ November 2016

Accepted: $28^{\text {th }}$ December 2016

\section{Keywords:}

space

material culture

structure

spatial analyses

theory, method

Swahili archaeology

built environment

\begin{abstract}
$A B S T R A C T$
Every paradigm in the history of archaeological theory has in some way dealt with space in interpreting the archaeological record; either bringing it into the spotlight or using it to assist description of other observed phenomena. This has resulted in a varied range of approaches to space, but also brought with it inherent problems. Paradigms once regarded as incompatible are now reconciled in mutual coexistence, but maintain little dialogue. Certain methods of spatial analyses have begun to be used as theory-neutral, and space often remains implicitly studied using methods as a set of tools, without exploration of adequate theory.

The goal of this paper is to present a perspective on how archaeologists may proceed in order to apply both analytical methods to seek patterns in the past and interpret past constructed space. Although space is an intangible entity, it is argued it may be seen as a human-made material culture that plays an active role in social processes. As a case study, I contrast the advantages and shortcomings of several archaeological studies concerned with the spatial structure of the Swahili house. It is argued that we need to actively engage approaches that reveal quantifiable patterns in the built environment, as well as consult more relativistic issues of perception, sensory experience, and social production and consumption of space.
\end{abstract}

\section{Introduction}

Spatial analyses in archaeology have so far been more widely applied and developed than discussed as theory-laden. This may be stated with reference to the long tradition of quantifying spatial properties of archaeological data, which extends back into the culture history period (if not earlier), that started to dominate archaeological research on a global scale nearly a century ago. On the other hand, space as a social agent in its own right, invoked and referred to in social relationships, has only properly been discussed in archaeology for the last three decades. It is not easy to disentangle the history of space as an object of theoretical considerations in archaeology, a component of methodological approaches and a context for a range of artefacts and features. The reason behind this complexity is that space has been referred to and incorporated in archaeological research with little sustained

*Corresponding author. E-mail: monika.baumanova@uclmail.net effort - all the more diversified when we speak of regional schools of archaeological thought as well as periods and locales under study.

One type of archaeological context where spatial considerations come into play is the study of the built environment. This has been most professed in research arenas such as household archaeology in the United States dealing both with prehistory and historical periods (e.g. Wilk, Rathje 1982; Santley, Hirth 1993; Parker, Foster 2012), archaeology of standing historic buildings in the United Kingdom (e.g. Fairclough 1992; Morriss 2000), or architectural history of medieval and historical buildings in Central and Eastern Europe (e.g. Macek 1997). More broadly across the globe, researchers have employed a number of theories and methods to explore and explain the form and organisation of past built environments. The popularity of the built environment in archaeological research has changed through the history of the discipline, which may have more to do with its perceived suitability for the specific nature of some archaeological enquiry, rather than the (un)availability of data. 
In this paper I present a short and inevitably selective review to demonstrate how archaeological paradigms of the last hundred years have dealt with the notion of space and highlight the consequences of this disciplinary history. These insights are shown to sometimes still hinder the progress of new research or prevent archaeologists filling in gaps in our understanding of the past. Using the example of structuralism and a case study dealing with household space in precolonial East Africa, I then demonstrate how insufficient communication between different schools of thought has led to the selective use or rejection of some methods, without full justification or criticism of their underlying theoretical reasoning. In conclusion, I argue that perhaps a new archaeological approach to space is in order, one that would allow archaeologists to explore its properties and roles in societies as a type of material culture, and so interpret space with more consistent explicitness.

\subsection{Approaches to space in the history of archaeology}

Every paradigm in the history of archaeological thought has in some way dealt with space. In the period of culture history that dominated archaeological research well into the 1960s in North America and Europe, the human past beyond the reach of the written record was very much understood through the concept of archaeological cultures. These cultures were characterized by their distribution in space represented as a certain sphere of influence on a map (Childe 1929, 5-6). Simultaneously, the existence or change in these archaeological cultures was explained by the migration of people across space, who carried their material culture with them (e.g. Kossinna 1911). The built environment was understood as a component in these material culture groups and characteristic of the associated people as well as an ultimate expression of their way of life (Childe 1929, 1950).

The analytical shift brought about with the New Archaeology of the 1960s, and elaborated for several decades onwards as it developed into the processual paradigm in archaeology, made use of spatial references to a much greater depth. It promoted, for example, spatially characterized sampling to study cultures and human activities. Human behaviour became increasingly understood and portrayed as "spatial" (Schiffer 1976, Clarke 1977). Archaeology owes to this period its significant advances in the field of scientifically-sophisticated spatial analyses that through mathematical and statistical description aimed to exhaustively describe the regularities in human use of space (Binford 1965; Hodder, Orton 1976). Although providing a range of tools for archaeologists, this paradigm did not move much beyond seeing space as a setting, a distribution of resources to be utilized, as exemplified in the seminal book by Kent Flannery, The early Mesoamerican village (Flannery 1976). As an extension to theoretical thinking popular in other social sciences (Simon 1959), landscapes and the built environment provided a reference point for studying patterns in the distribution of portable material culture - and, apart from that, they were mostly studied as an example of utilization of resources, a statement of people's optimal behaviour in a given setting (for a summary, see e.g. Rossignol 1992).
However, especially among archaeologists interested in more recent periods of the human past and themes such as urbanism and complexity, the processual stream of thought prompted inquiry into potential patterns behind the distribution of central places, specific building traditions, monumentality and the complexity of the tangible components of the built environment (Smith 1976).

The post-processual school of thought was successful in highlighting how problematic this approach might be. Although primarily not focused on developing new analytical tools for spatial analyses, the post-processual paradigm brought us countless case studies demonstrating that space is not just a setting, but also a reference to social phenomena, a tool of social change and contextual interpretation (e.g. Hodder 1982b; 2001; Shanks, Tilley 1988). Constructed space also needs to be contextualized in terms of temporality and the way people understand their production of built space in relation to the passage of time (Simonetti 2013; Zubrow 2013). This stream of thought has been elaborated upon in archaeological studies of architecture (e.g. Johnson 1993; Parker Pearson, Richards 1994; Steadman 2015) that in turn greatly influenced the way archaeologists conceptualize space, having moved from seeing it as a reflection of culture towards a "habit of mind" (Gurevich, Howlett 1992, 4) and an active agent in social negotiations (Laurence 1996).

While processual and post-processual lines of reasoning may seem incompatible given their fierce criticism of each other, they are now reconciled in mutual coexistence, but unfortunately maintain little dialogue (but note Cochrane, Gardner 2011). For archaeologies of space in particular this poses a problem. If we look at it as a mosaic, the naturalsciences-derived, method-driven approaches generally aim to quantify the patterns of the preserved parts in the mosaic and find regularities in their distribution, while the post-processual viewpoint is more concerned with deriving what pieces and colours might be missing. Neither approach makes exhaustive use of the data that are accessible to an archaeological enquiry on space, nor are they without inherent shortcomings. Processual archaeology never really seriously considered space for the properties it shares with tangible material culture, as both can be produced, altered, contextually interpreted or consumed. Post-processual archaeologies maintained the relationship of theory and method less rigorously, which has also allowed for relative openness to plurality and decreased argumentative strength of interpretations.

If we consider the origin and nature of these shortcomings in more detail, we may begin to disentangle how the two main perspectives on space may be used to complement each other and begin to remedy some of their respective disadvantages.

\section{Analyses of constructed spatial features}

In archaeological spatial analyses, space is rarely the ultimate object of interpretation. In fact, the goal is rather to 
understand how space is incorporated into human use of the tangible world where the use of intangible space is implicit.

More than sixty years ago, Hawkes proposed his "ladder of inference", which described what aspects of the past may be accessible to archaeology (Hawkes 1954). Hawkes argued that archaeology is suited to obtain reliable data about the lowest tier of the "ladder", represented by past technology and transformation processes that affect archaeological sites, and as we move up the "ladder" we may recover less and less knowledge on subsistence economics and political dynamics, with the spiritual belief and thinking of the past people virtually beyond the reach of archaeological enquiry.

Although archaeology has matured and advanced much further than where it was in the 1950s, I still argue that the underlying awareness, if not fear, of the ladder of inference remains inherent to the discipline, and to how it is willing to understand space. Whenever space had to do something with technology, subsistence or environment, it was much more studied by research. Making intangible space an explicit object of study associates it with the category of thought life and ideology, and also makes it potentially less verifiable and defensible on the grounds of "hard" scientific method. The suitability of a range of natural science and mathematical methods, as well as computer software and technologies for archaeological enquiry, has in many instances led to the situation that their availability, rather than advances in theory, has guided the research, in the sense that research questions were driven by what was possible with the new technologies rather than by theoretically-derived conceptual questions. The theoretical content then referred to a middlerange theory of methodological application rather than the social theory of past human practices (e.g. Kuna 2004). The criticism of more recent decades has pointed out that spatial analyses should stop being presented as a statistical exercise, a stage to go through in archaeological work - primarily because such an approach has far reaching connotations if it becomes an implicit "paradigm" of its own.

In so doing, certain aspects of space may repeatedly become subject to analysis while others are avoided. Let us consider the medieval walls from Great Zimbabwe, as an example of a spatial feature and a site distant enough in date and context from the European mindset, to demonstrate that this is an issue of global archaeology. The processes that went into the building of the highly sophisticated stone walls of this UNESCO World Heritage Site were for a long time assessed as a testament to technology, which was first denied African origin, and subsequently its sophistication, following the argument that the absence of corners built into the monumental structure signifies a lack of technological knowledge (for the history of this research, see Hall 1990). Later, the walls began to be understood as part of the local cattle-keeping economy and power politics, but it was only a recognition of their potential role in the local cosmologies, social phenomena and their development through time (Ranger 1999) that allowed archaeologists to explain the size, form and logic of placement of the walls (Huffman 2001; Pikirayi 2001). This became possible not only with more data being recovered from the site, but primarily with advances in theory (for an overview, see e.g. Ucko 1995; Garlake 2002, 141-162), that allowed researchers to argue conclusions aspiring to shed light on the higher tiers of the "ladder of inference".

This example goes to show that the technology with which walls are built can be of importance only in the context of some questions, while their relative height, configuration with other features on site, and how they structured space may be at other times much more significant. It derives that if we choose to more frequently consider certain objectives of wall-building because we assume that the data available can more reliably be analysed in reference to those objectives, we are by extension suggesting that our present-day concerns were also the major concerns of past people. Archaeological research which is led by the availability and potential of methods - and solely by the natural science hypothesistesting approach to theory (Neustupny 2007) - is hence in danger of incorporating implicit assumptions that bias our understanding of the past.

In the case of Great Zimbabwe, only 50 years of further research allowed a change in the politically-, and also theoretically-, skewed interpretation and thus contextually explain the walls. If we shy away from analysing the space itself, how it is organised, we have already made an interpretation and chosen to ascribe the walls that structure it with a specific meaning. The so-called "optimal choices" behind wall-building in every culture we study are going to be the same. This problem has also been highlighted in criticism of the optimal foraging theory, the major flaw of which was portraying adaptation as an evolutionary process where culture inhibits optimality, so that behavioural models emerge both as a consequence of and explanation for observed patterns (Ingold 2000, 38). A similar problem appears if we compare ethnographically- and archaeologically- recorded communities for which a similar basis of economy is assumed (e.g. Lane 2015).

In many ways, the post-processualist approaches of the last thirty years tried to get around this problem: one of its main achievements being the demonstration that space may also be produced and consumed, similarly to pottery or metal artefacts (e.g. Tilley 1994). However, one of the shortcomings of post-processual research on space is a more relaxed maintenance of the mutual interdependence between theory and method, an imbalanced weight of reasoning towards, for example, ethnographic parallels, or treatment of methods as theory-neutral. A good example is the field of structural theory and structural analyses, which in essence stands somewhat on the borderline between analytical and interpretive archaeologies.

\section{Structuralism and structural analyses of space}

Structural approaches as a school of thought in archaeology have been developed as a theory as well as a set of analytical tools for studying space, yet often they have been subject to 
misconceptions about their applicability. Structural analyses in archaeology evolved in an extension to a wider research direction in social sciences. In archaeology specifically, structural approaches characterised a substantial part of post-processualist research as represented by the now classic volume Symbolic and Structural Archaeology edited by Ian Hodder (Hodder 1982a). They are based on the idea that people think in a language and when they act on their thinking this quality is transferred onwards, including their material culture. Structuralist approaches were aimed at disentangling this meaning from material culture, which was argued to preserve some of its linguistic qualities, e.g. binary oppositions such as light and dark, strong and weak (Lévi-Strauss 1969). Many disciplines were making use of these principles, including: anthropology, social geography, architecture, sociology and psychology (Bourdieu 1990). This also spurred the adaptation of a range of analytical methods for social sciences such as graph theory (Hage, Harary 1983), GIS (e.g. Llobera 1996), and most recently network analysis (Scott 2000). Perhaps the most influential volume among archaeologists was based on research from UCL's Bartlett School of Architecture (Hillier, Hanson 1984; Hillier 1996) and the Institute of Archaeology (Bevan, Lake 2013), which also prompted more research on the materiality of networks (Knappett 2013).

\section{Gede Ruins - Kenya}

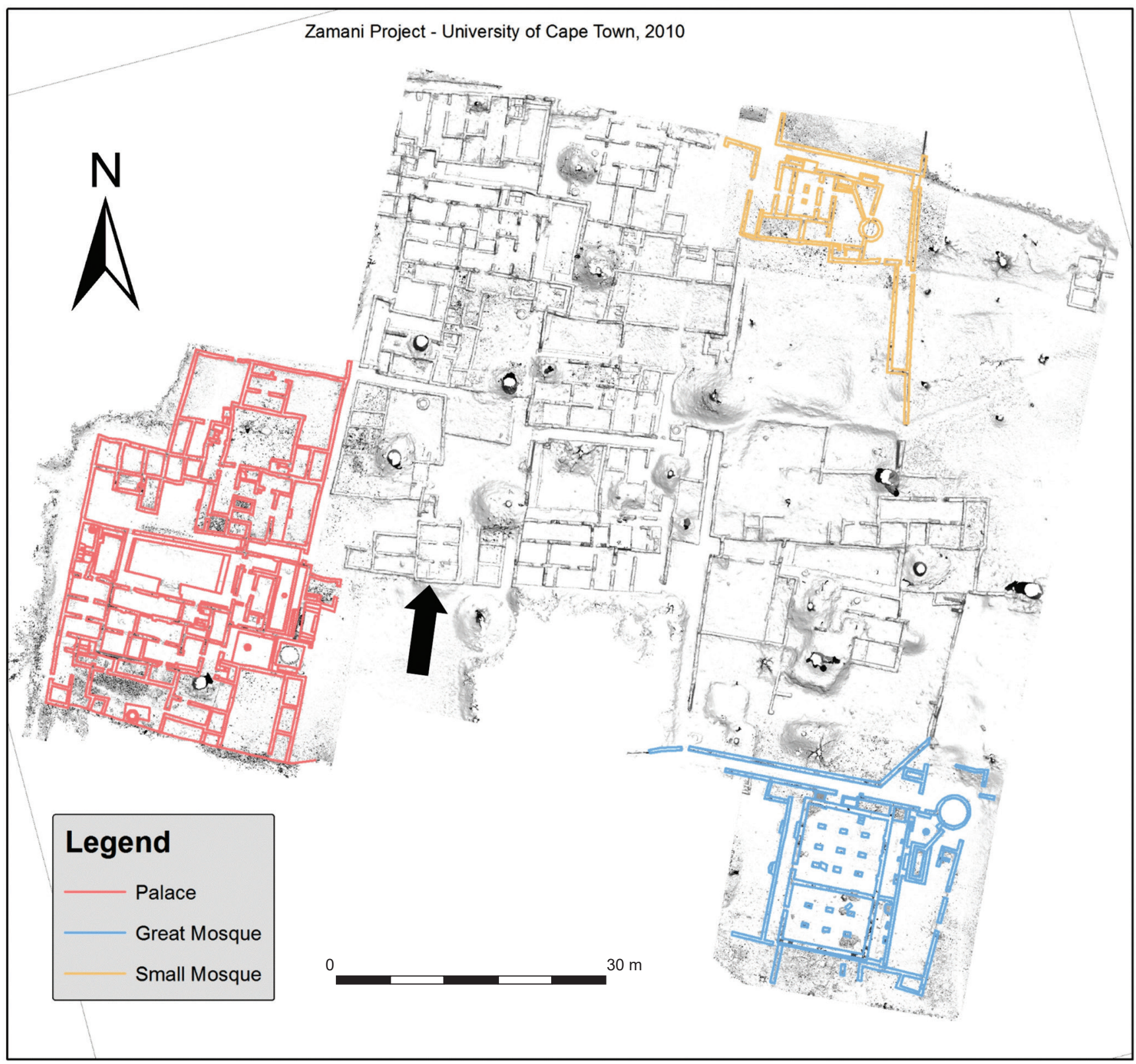

Figure 1. A GIS plan of the stone-built architecture at Gede, a pre-colonial deserted Swahili town on the coast of Kenya. The arrow shows the location of the "House of the Porcelain Bowl", shown in detail in Figure 2 (adapted GIS plan based on field surveys of the Zamani project). 
Structural approaches are in some ways analogical to approaches that focus on the style and form of material culture. Speaking about the built environment, they compare its properties to establish the level of relative difference and highlight patterns in the configurations of its elements, contrasting, for example, walls and open space unobstructed by construction. Structuralist thinking has been criticised in sociology and anthropology for lack of concern for people's agency, or the capacity to do things differently in structurally-similar settings (e.g. Giddens 1993). However, the archaeological record is most often a record of repeated social rather than individual action, especially when dealing with constructed space or space in a built environment. It should be highlighted that individual agency is simply not the quest of structuralist reasoning. In this context, it resonates well that individuals are invoked across the field of current archaeology in contexts to which the individual persona is not always relevant, portrayed as having a relationship with society rather than constituting an inseparable entity (Thomas 2004). Research questions in structuralist studies hence need to be well grounded theoretically so as to target the social collective agency and recognise their limited scope.

Understanding structural analyses may help us to disentangle why and how we should choose to conceptualise space as a type of material culture. By building or abstaining from building, as well as by making any modifications to the environment that in turn affect human perception, people produce space. Although space is an intangible (abstract) phenomenon, it may so be constructed, altered and structured by tangible features. We may then see it as a type of material culture (for comparison, see contributions to Hicks and Beaudry 2010). The purpose of its materiality may then be understood to act on human perception, as a tool of non-verbal communication (Cosgrove, Daniels 1988; Rapoport 1990; Smith 2003), which may be invoked in a range of contexts and for a number of goals.

In reference to the archaeological record, we may not be able to determine what were the activities or goals for which specific spaces were the most relevant, just as we most often cannot distinguish between conscious and subconscious choices people made in the past in acting on the properties of space. It is possible that when there is observed continuity in spatial arrangements, the associated social connotations may have (not) continued; i.e. change may occur without spatial representations. However, we should still be able to analyse and highlight patterns, which in this case derive not from the past uses of space, but from the properties given to space through human action. These are intangible because of the nature of space, yet real (Ingold 2000), providing opportunities, i.e. affordances, for action (Gibson 1979). It is then possible to determine for what contextual uses specific places were better suited than others on the basis of a comparison of their recurrent contextual qualities. Data obtained in an excavation and survey of tangible heritage may then be checked for correlation with the interpretation of relative prominence or role of specific places within a house or a town; for example, patterns in the location of larger avenues and shorter winding streets, relative privacy, higher or decorated walls in certain spaces, or positioning of doorways and access routes.

\section{Swahili house power model}

Structural approaches have been used in a number of regions to analyse space in past societies since the 1980s, but not always in a "complete package" of theory and method. In Africa, they were applied as a stream of theoretical reasoning as well as an analytical toolkit among other methods of data analyses, only rarely developing both in contextual argumentation (Monroe 2014, 200-203; Baumanova, Smejda, 2017). The case study presented here aims to highlight what the problems of the former selective approaches were, focusing on the pre-colonial Swahili towns of the $10^{\text {th }}$ to $16^{\text {th }}$ century CE.

The Swahili were an early African Muslim culture that built cities on the east coast of Africa which consisted of quarters of stone buildings (Figure 1), as well as wattle-anddaub architecture. They were greatly involved in the Indian Ocean trade of the period, participating in early globalisation processes and far-reaching economic and social networks that interconnected the Indian Ocean world (LaViolette 2013).

The Swahili house power model is an ethno-archaeological study published first in 1982 (Donley 1982). In her paper, the author argued that spatial structure of houses observed ethnographically was socially meaningful not only in the present, but extended further into the past because a similar house layout had been documented on archaeological sites (Figure 2). The conclusions included the assumption that female space was segregated and the activities of women were secluded in the most private rooms of the house, i.e. most distant from the entrance (Donley 1982). The approach and conclusions of the study have recently been heavily criticized for disregarding the political atmosphere in which the ethnographic part of the study was undertaken, as well as for its overall normative approach that extended its results to the past (Fleisher 2015). What made the original paper not stand the test of time might be, I argue, the inconsistent use of theory and method that was referred to but underdeveloped in the given context. Donley-Reid's paper and her subsequent studies on the topic (Donley 1982; Donley-Reid 1987; Donley-Reid 1990) claimed to be structural studies, yet they used comparative theory in terms of methodology, considering similarities and differences in the use of house form and layout in an ethnographic and archaeological context, assuming that the observed regularities were meaningful. However, Donley-Reid never really applied the methods of structural spatial analyses that would formally describe the observed phenomena (as shown in Figure 2). Yet she interpreted her study on the background of structural theory, weakening her argument by separating an inherently-associated theoretical and methodological reasoning. Donley-Reid's study aimed to answer questions 


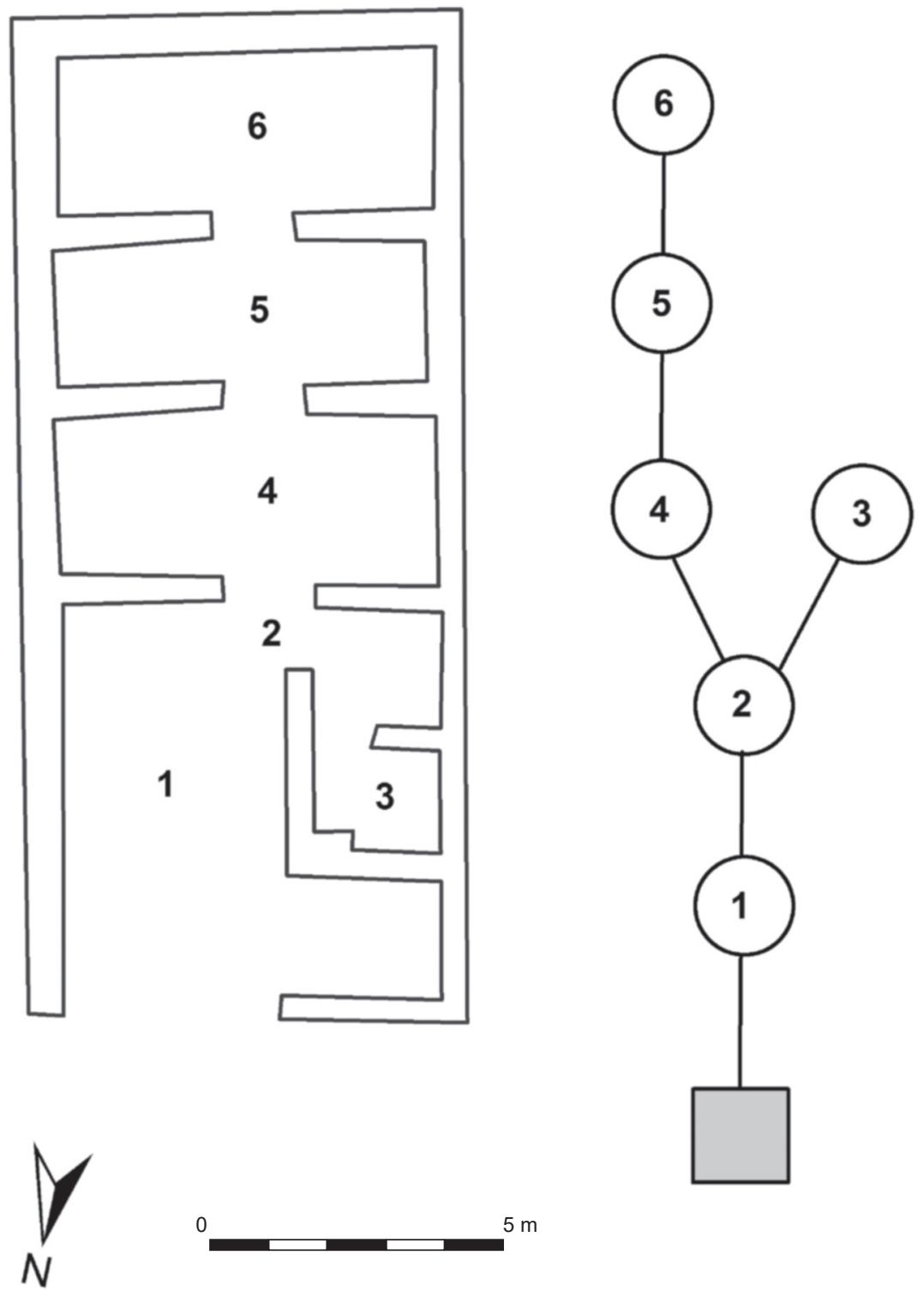

Figure 2. An example of the layout plan of Swahili stone houses, the so-called 'House of the Porcelain Bowl', Gede, Kenya (based on a GIS plan by the Zamani project). The access analysis graph shows the interconnectedness of the rooms and the court within the house, highlighting how the space is structured in terms of relative access depth, from the most public (closest to the entrance) to the most private (most distant from the entrance).

about the distribution of specific activities in space, which may and are being better answered with new detailed excavations (e.g. Wynne-Jones 2013; Wynne-Jones, Fleisher 2016).

On the other hand, any analyses of archaeological deposits cannot substitute the informative potential of space and the way space influences human bodily experience and sensory perception through its relational configuration. Yet, the distribution of tangible material culture and ecological data as representations of specific activities as well, continue to be used for interpretations of space. This type of indirect data have recently been argued to represent spatial territories within a Swahili town site, although space was defined just as a reference area (Wynne-Jones, Fleisher 2016, 1), without an argumentation that would shed light on how the newly proclaimed territory differs from, for example, the once popular classification of a so-called activity area. If more effort was directed to employing social theories of spatial behaviour, the concept of territorial behaviour could be expanded as a social phenomenon. This has been well-defined in sociology and history with regard to the concept of control and temporality (for an overview, see Sack 1986); hence, one of the tasks of archaeology could be how territoriality would be represented in the configurations of space.

In her archaeological research on precolonial houses, Linda Donley-Reid should be given credit for being the first to open up the theme of research concerned with the structure of space in this context. Although her approach was afterwards justly criticised (Fleisher 2015), the present paper has highlighted other limitations in the theoretical and methodological outlook of Donley-Reid's studies (1982; 1987; 1990), which did not explore fully the analytical, comparative and interpretive potential of structural perspectives on space. Overall, it can be argued that structural 
approaches in archaeology should not be abandoned, but rather constructed space should be explored more explicitly and systematically. One way to do so appears to be through recognising space as an (abstract) type of material culture, and making it a recognised object of study. In doing so, we will need to come to terms with the inherent properties of the materiality of space which allows it to be invoked in a range of contexts and activities; yet to a different degree, making some of its subsequent interpretations more likely than others. Archaeologists should be well familiar with this process from interpreting the physical properties of other types of objects (Fowler 2013).

\section{Conclusion}

The issue of space is a difficult one in archaeology. The explicit development of its theoretical meaning has been left unexplored well into the 1980s - and also because the discipline sometimes grapples with the question whether and on what levels the materiality that it studies may or may not equal tangible objects.

The incompleteness of the archaeological record affects all paradigms and approaches, which means that not all theories and methods can be successfully used in all contexts. However, they can often be made to provide complementary answers, as long as we pay due attention to the development and adaptation of the disciplinary theoretical and methodological toolkit. With regard to space, analyses of tangible material culture including buildings, can only provide data that refer to space indirectly. Only description and analyses of space in its own right can provide us with the highly relevant direct information about how it was produced, used, perceived, understood and consumed in the past. Through integrating the development of archaeological theory and method in unison, we can provide complementary questions and answers to those generated through the study of other types of material culture.

We as archaeologists need to find more ways to help us understand space as material culture: we have after all done it for more than a century, for example, with pottery. When comparing spatial organisation, we need to more systematically engage in locating variability in patterns. Collaboration with other social sciences, such as environmental psychology and geography, may also help, where studies on this topic have a longer history of research (Lynch 1960). Interdisciplinary studies point towards understanding space and its structure as entangled in social and institutional power, performance, and acting on and being part of human emotional life received through sensory engagement with the world (Crouch 2003; Watterton 2013).

Explorations of space as material culture, and more specifically with the use of structural analyses, explore the order that people impose on themselves and their visitors - in what setting people choose to distance themselves or encounter others. The big question for many critics of approaches that integrate structural theories is that we cannot determine whether people intentionally structured their environment or if they were building without any preconceived plan. As archaeologists, we perhaps cannot derive people's intentions directly. But we can speak about patterns of reference points, study what these might mean socially, and derive likely conclusions. However, we should not surrender to the illusion that some theory of natural sciences or mathematics alone is going to make our conclusions sound. Archaeology will always need the development, or at least the adaptation, of social science theories for its further advancement, and we should proceed in this direction mindful of the fact that the discipline's greatest strength is in understanding the complex social meaning of material culture.

\section{Acknowledgements}

This paper was written with the support of the author's Marie Skłodowska-Curie Actions Individual Global Fellowship (No. 656767 - TEMPEA). I am grateful to the reviewers for providing comments on an earlier draft of this paper. I would like to thank Martin Kuna and Peter Demjan for providing insights and inspiring discussion on the topic of this paper at the panel on New Theoretical Perspectives in Central European Archaeology, organised at 3rd CE TAG 2016 in Bratislava. The GIS plan of Gede ruins was kindly provided by Heinz Ruther of the Zamani Project, University of Cape Town.

\section{References}

BAUMANOVÁ, M., ŠMEJDA, L., 2017: Structural dynamics of spatial complexity at the "Palace of Gede", Kenya. Azania: Archaeological Research in Africa, DOI: 10.1080/0067270X.2017.1283095.

BEVAN, A., LAKE, M. 2013: Computational approaches to archaeological spaces. Left Coast Press, Walnut Creek.

BINFORD, L. R. 1965: Archaeological Systematics and the Study of Culture Process. American Antiquity 31, 203-210.

BOURDIEU, P. 1990: The logic of practice. Polity Press, Cambridge. CHILDE, V. G. 1929: The Danube in prehistory. Clarendon Press, Oxford. CHILDE, V. G. 1950: The Urban Revolution. Town Planning Review 21, 3-17. CLARKE, D. L. 1977: Spatial archaeology. Academic Press, London.

COCHRANE, E., E., GARDNER, A. 2011: Evolutionary and interpretive archaeologies: a dialogue. Left Coast Press, Walnut Creek.

COSGROVE, D. E., DANIELS, S. 1988: The Iconography of landscape: essays on the symbolic representation, design, and use of past environments. Cambridge University Press, Cambridge.

CROUCH, D. 2003: Spacing, performing, and becoming: tangles in the mundane. Environment and Planning A 35, 1945-1960.

DONLEY, L. 1982: House power: Swahili space and symbolic markers. In: Hodder, I. (Ed.): Symbolic and structural archaeology. Cambridge University Press, Cambridge, 63-73.

DONLEY-REID, L. 1987: Life in the Swahili town house reveals the symbolic meaning of spaces and artefact assemblages. African Archaeological Review 5, 181-192.

DONLEY-REID, L. 1990: A structuring structure: the Swahili house. In: Kent, S. (Ed.): Domestic Architecture and the Use of Space. Cambridge University Press, Cambridge, 114-126.

FAIRCLOUGH, G. 1992: Meaningful Constructions - Spatial and Functional-Analysis of Medieval Buildings. Antiquity 66/251, 348-366. FLANNERY, K. V. 1976: The Early Mesoamerican village. Academic Press, New York. 
FLEISHER, J. 2015: Situating the Swahili house. In: Wynne-Jones, S., Fleisher, J. B. (Eds.): Theory in Africa, Africa in theory: locating meaning in archaeology. Routledge, New York, 72-78.

FOWLER, C. 2013: Relational personhood as a subject of anthropology and archaeology: comparative and complementary analyses. In: Garrow, D., Yarrow, T. (Eds.): Archaeology and Anthropology: understanding similarity, exploring difference. Oxbow Books, Oxford, 137-159.

GARLAKE, P. S. 2002: Early Art and Architecture of Africa. Oxford University Press, Oxford.

GIBSON, J. J. 1979: The ecological approach to visual perception. Houghton Mifflin, Boston.

GIDDENS, A. 1993: New rules of sociological method: a positive critique of interpretative sociologies. Stanford University Press, Stanford.

GUREVICH, A. I., HOWLETT, J. 1992: Historical anthropology of the Middle Ages. University of Chicago Press, Chicago.

HAGE, P., HARARY, F. 1983: Structural models in anthropology. Cambridge University Press, Cambridge.

HALL, M. 1990: "Hidden history": Iron Age archaeology in Southern Africa. In: Robertshaw, P. (Ed.): A History of African archaeology. J. Currey, London, 59-77.

HAWKES, C. 1954: Archaeological Theory and Method: Some Suggestions from the Old World. American Anthropologist 54/2, 155-168.

HICKS, D., BEAUDRY, M. C. (Eds.) 2010: The Oxford handbook of material culture studies. Oxford University Press, Oxford.

HILLIER, B. 1996: Space is the machine: a configurational theory of architecture. Cambridge University Press, Cambridge.

HILLIER, B., HANSON, J. 1984: The social logic of space. Cambridge University Press, Cambridge.

HODDER, I. 1982a: Symbolic and structural archaeology. Cambridge University Press, Cambridge.

HODDER, I. 1982b: Symbols in action: ethnoarchaeological studies of material culture. Cambridge University Press, Cambridge.

HODDER, I. 2001: Archaeological theory today. Polity Press, Cambridge.

HODDER, I., ORTON, C. 1976: Spatial analysis in archaeology. Cambridge University Press, Cambridge.

HUFFMAN, T. N. 2001: The Central Cattle Pattern and interpreting the past. Southern African Humanities 13, 19-35.

INGOLD, T. 2000: The perception of the environment: essays on livelihood, dwelling and skill. Routledge, London.

JOHNSON, M. 1993: Housing culture: traditional architecture in an English landscape. Smithsonian Institution Press, Washington, D.C.

KNAPPETT, C. 2013: Network analysis in archaeology: new approaches to regional interaction. Oxford University Press, Oxford.

KOSSINNA, G. 1911: Die Herkunft der Germanen: zur methode der Siedlungsarchäologie. C. Kabitzsch, Würzburg.

KUNA, M. et. al. 2004: Nedestruktivni archeologie. Teorie, metody a cíle / Non-destructive archaeology. Theory, methods, and goals. Academia, Praha.

LANE, P. J. 2015: Iron Age imaginaries and barbarian encounters: British prehistory's African past. In: Wynne-Jones, S., Fleisher, J. B. (Eds.): Theory in Africa, Africa in theory: locating meaning in archaeology. Routledge, New York, 175-200.

LAURENCE, R. 1996: Roman Pompeii: Space and society. Routledge, London.

LAVIOLETTE, A. 2013: The Swahili World. In: Mitchell, P. and Lane, P. (Eds.): The Oxford handbook of African archaeology. Oxford University Press, Oxford, 901-914.

LÉVI-STRAUSS, C. 1969: The elementary structures of kinship. Beacon Press, Boston

LLOBERA, M. 1996: Exploring the topography of mind: GIS, social space and archaeology. Antiquity 269, 612-622.

LYNCH, K. 1960: The image of the city. Technology Press, Cambridge Mass.
MACEK, P. 1997: Standardni nedestruktivní stavebně historický průzkum. Státní ústav památkové péče, Praha.

MONROE, J. C. 2014: The precolonial state in West Africa: building power in Dahomey. Cambridge University Press, Cambridge.

MORRISS, R. K. 2000: The Archaeology of buildings. Tempus, Stroud and Charleston.

NEUSTUPNÝ, E. 2007: Metoda archeologie. Aleš Čeněk, Plzeň.

PARKER, B. J., FOSTER, C. P. 2012: New perspectives on household archaeology. Eisenbrauns, Winona Lake, Ind.

PARKER PEARSON, M., RICHARDS, C. 1994: Architecture and order: approaches to social space. Routledge, London.

PIKIRAYI, I. 2001: The Zimbabwe culture: origins and decline of southern Zambezian states. AltaMira Press, Walnut Creek.

RANGER, T. O. 1999: Voices from the rocks: nature, culture \& history in the Matopos Hills of Zimbabwe. J. Currey, Oxford.

RAPOPORT, A. 1990: The meaning of the built environment: a nonverbal communication approach. University of Arizona Press, Tucson.

ROSSIGNOL, J. 1992: Introduction. In: Rossignol, J., Wandsnider, L. (Eds.): Space, time, and archaeological landscapes. Springer, New York, $3-20$.

SACK, R. D. 1986: Human territoriality: its theory and history. Cambridge University Press, Cambridge.

SANTLEY, R. S., HIRTH, K. 1993: Prehispanic domestic units in western Mesoamerica: studies of the household, compound, and residence. Boca Raton, CRC Press, Boca Raton.

SCHIFFER, M. B. 1976: Behavioral archaeology. New York, Academic Press, New York.

SCOTT, J. 2000: Social network analysis: a handbook. SAGE Publications, London.

SHANKS, M., TILLEY, C. Y. 1988: Social theory and archaeology. University of New Mexico Press, Albuquerque.

SIMON, H. 1959: Theories of decision making in Economics and Behavioral Science. American Economic Review 49, 253-283.

SIMONETTI, C. 2013: Between the vertical and the horizontal: time and space in archaeology. History of the Human Sciences 26, 90-110.

SMITH, A. T. 2003: The political landscape : constellations of authority in early complex polities. University of California Press, Berkeley.

SMITH, C. A. 1976: Regional analysis. Academic Press, New York.

STEADMAN, S. R. 2015: Archaeology of domestic architecture and the human use of space. Left Coast Press, Walnut Creek.

THOMAS, J. 2004: The Great Dark Book: archaeology, experience, and interpretation. In: Bintliff, J. L. (Ed.): A companion to archaeology. Blackwell, Oxford, 25-36.

TILLEY, C. 1994: A Phenomenology of landscape: Places, paths and monuments. Berg, Oxford.

UCKO, P. J. 1995: Theory in archaeology: a world perspective. Routledge, London.

WATTERTON, E. 2013: Landscape and Non-Representational Theories. In: Howard, P., Thompson, I., Waterton, E. (Eds.): The Routledge companion to landscape studies. Routledge, London.

WILK, R. R., RATHJE, W. L. 1982: Household archaeology. American Behavioral Scientist 25, 617-639.

WYNNE-JONES, S. 2013: The public life of the Swahili stonehouse, $14^{\text {th }}-15^{\text {th }}$ centuries AD. Journal of Anthropological Archaeology 32/4, 759-773.

WYNNE-JONES, S., FLEISHER, J. 2016: The multiple territories of Swahili urban landscapes. World Archaeology (DOI: 10.1080/00438243.2016.1179128), 1-14.

ZUBROW, E. B. W. 2013: Prehistoric place: Studies in material culture, time and space. In: Gheorghiu, D., Nash, G. (Eds.): Place as material culture: objects, geographies and the construction of time. Cambridge Scholars Publishing, Cambridge, 13-33. 